\title{
Integrative Analytical Assessment: A Hybrid Method for Facilitating Negotiation
}

\author{
Kan Chen and Steven E. Underwood
}

Accurate assessment of interests and possible agreements is often the decisive factor in successful negotiation. Particularly in complex negotiations, effective assessment practices can increase a negotiator's awareness of opportunities and assist in the design of superior agreements. Unfortunately, a common pitfall in many negotiations is inadequate preparation and assessment. Even when the incentive for cooperation is high, inadequate assessment will often result in failed negotiation or inferior agreements. With limited awareness of their own or their opponent's interests, and the possible means of meeting those interests, unapprized negotiators are unlikely to make the most of their efforts.

In response to such problems, we propose that integrative analytical assessment procedures, performed by a neutral intermediary, can assist parties with a desire to cooperate in complex negotiations. An integrative analytical assessment, or IAA, is a thorough, step-by-step process designed to assist negotiating parties in assessing and analyzing information that is useful for generating agreements. The approach is integrative in two senses. First, the social process perspective is integrated with formal analytical methods. Second, an IAA emphasizes integrative (win-win) rather than distributive (win-lose) negotiations. This article will describe a specific case that illustrates how the approach helped two units in a business organization reach a mutually satisfactory agreement after a breakdown in their negotiation.

\section{Conceptual Origins}

Negotiation has been studied and facilitated from both the perspective of social process and the perspective of formal analysis. Current negotiation practice is well grounded on the social process perspective, including the possibilities of third party intervention through mediation, fact-finding, and arbitration (Green-

Kan Chen is Professor of Electrical Engineering and Computer Science at the University of Michigan, Ann Arbor, Michigan 48109-2122. Steven E. Underwood is a candidate for a Ph.D. degree in the Program in Urban, Technological, and Environmental Planning, 506 East Liberty, Ann Arbor, Michigan 48109-2209. 
baum, 1986). Prescriptive developments in the social process perspective have been advanced by scholars from such disciplines as social psychology, organizational development, and law. The social process perspective includes the wellknown prescriptive work on the "principled negotiation process" to facilitate integrative negotiations (Fisher and Ury, 1981).

The perspective of formal analysis, on the other hand, has only recently found its way into real practice in negotiation, ranging from business negotiations to international treaties (Lax and Sebenius, 1986; Sebenius, 1984). Such formal analyses, anchored in game theory and decision theory, have been developed by experts from such fields as mathematical psychology and operations research, among others. Game theory has been used to analyze conflict situations in both the private sector (McDonald, 1975) and the public sector (Brams, 1975 and 1985), and procedures have been developed to operationalize the theory of metagames for conflict analysis (Fraser and Hipel, 1984). Group decision theory has been applied to search for win-win solutions through Paretian analysis ${ }^{1}$, which determines the set of feasible solutions in which no party can gain more without another party taking a loss (Raiffa, 1982). These formal approaches to strategic analysis are distinguished from the application of formal impact models in negotiation, as exemplified by Dutton and Kraemer's (1985) use of fiscal analysis models in urban and regional negotiations, or the use of adaptive environmental assessment in environmental negotiations (Holling, 1978). The former are models of strategic decision making, while the latter are models of the substantive phenomena.

The potential synergism between the social process and the formal analytic perspectives for conflict resolution is clear. Without effective intergroup communication and problem-solving processes, the parties could remain antagonistic and there would be little opportunity for productive negotiation. Without a relevant analysis, there would be little systematic or objective support for identifying joint gains, and one would not be able to assess whether an agreement measures up to the potential for joint gains. However, while the integration of the social process and formal analytic perspectives on conflict resolution has been suggested and experimented in the academic environment (Quinn et al., 1985; Raiffa, 1982), such integration has not been widespread in real practice. One attempt in this direction has been the approach of "decision conferencing" (Phillips, 1984), in which the group process is combined with real-time decision analysis, often with the aid of a computer support system, as a means to help problem solving. However, the element of conflict has been nominal or minimal in such applications.

Another attempt at integrating formal analysis with a systematic communication process was in the form of "value-oriented social decision analysis," or VOSDA (Chen et al., 1979). The VOSDA procedure uses multi-attribute utility analysis to improve communications among disparate interest groups who are in conflict over a specific issue, such as a technological issue. The VOSDA procedure consists of three stages:

1. Problem clarification;

2. Action and consequence identification; and

3. Policy determination and description. 
The VOSDA procedure has been applied to help communications among elected officials at the local government level on a solid waste treatment issue, and communications among interest groups at the state government level on an energy issue, but stopped short of resolving conflicts (Chen and Mathes, 1986).

Integrative analytical assessment in many respects is an extension of VOSDA. Both approaches aim to combine the social process and the formal analytical perspectives, but IAA carries the VOSDA approach forward by suggesting options and processes for reaching agreement. To emphasize integrative rather than distributive conflict resolution, IAA combines VOSDA with Paretian analysis (Raiffa, 1982) from the formal analytical perspective, and with the principled negotiation process (Fisher and Ury, 1981) from the social process perspective, as shown by the diagram in Figure 1.

FIGURE 1

Integration of Process and Analytical Perspectives

Social Process Perspective

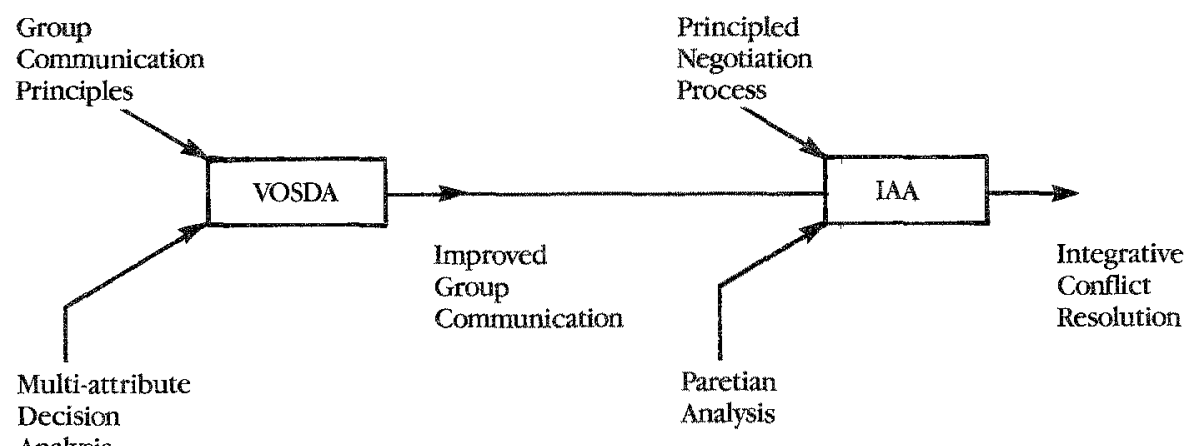

Formal Analytical Perspective

While the IAA approach may facilitate negotiation in a wide variety of conflict situations, ranging from international disputes to labor-management bargaining, our initial experiment focused on a business negotiation. Essentially, this negotiation was a two-party, nonzero-sum game, with practical but minor variations (namely, that each side included nonmonolithic interest groups, that there were linkages between two or more negotiations, and that the analysts were included as third-party facilitators).

In business negotiations between two potential partners, there are generally both conflictual elements (dividing up a pie between the partners) and cooperative elements (building up a larger pie before it is divided). In such situations, there may be opportunities for exploring Pareto optimal, or at least Pareto superior (win-win), agreements that are better than no agreements, or better than some initial agreements, in the sense that both partners can reap higher benefits.

In reality, however, the actual processes of business negotiations are often ineffective and inefficient, and results are not compared with the Pareto optimum. The reason for this deficiency seems not so much because the negotiators do not 
know the concept of Pareto optimality as because they do not have any timeproven operational procedure to jointly explore Pareto superior agreements. For example, few negotiators do quantitative tradeoff analysis, (say, for the tradeoff between profit and management control, or between profit in local currency and profit in foreign exchange if the two are not readily convertible in the open market); and if they do, the negotiators are reluctant to share the internal tradeoff analysis with the other side for fear that such information may be exploited to their disadvantage. Yet such information sharing, at least with a third-party analyst up to a point, has the potential for yielding joint gains and is essential for Paretian analysis. There is a need for an operational procedure to facilitate more integrative bargaining in cases where the negotiating parties suspect that there are opportunities for joint gain through agreement, but these opportunities are unclear due to the ambiguity or complexity of the issues, or imprecise communication between the parties.

\section{The Meter Reading Case}

The authors first developed and applied the IAA concept in the summer of 1985 as a hybrid method for facilitating a difficult negotiation between the Detroit Edison Company and its wholly-owned subsidiary, Syndeco, Inc., on a business plan and contract for meter reading services. Detroit Edison had traditionally provided meter reading services to its customers with its own meter reading force, occasionally adjusting to changes in demand with the assistance of temporary employees. However, the top management of Detroit Edison decided earlier that year to reduce costs and management difficulties by limiting Detroit Edison's own meter reading operations to a stable core and by contracting out the excess portion of the business to independent contractors. Representatives of Detroit Edison informed managers at Syndeco of their plans, and asked the Syndeco managers if they would be willing to work with the parent company in developing a plan for the operations.

As business negotiations go, there was a relatively high level of incentive for the two business units to cooperate in developing a mutually acceptable plan. Syndeco was in the business of supplying technical services to utility companies and was eager for the opportunity to supply its parent company with the meter reading services. It was in the interest of Detroit Edison, as the parent, to assist its subsidiary in remaining a viable business unit. Nevertheless, at the level of the organization where the meter reading contract negotiations occurred, these incentives were complicated by other objectives that interfered with the negotiations. In fact, the parties were clearly in conflict over several issues, especially the unit cost of the proposed meter reading service. The meter reading operation in Detroit Edison had a mandate to limit the cost of its services. Similarly, as an independent business unit, Syndeco was also cost-conscious and had relatively severe cash flow and break-even constraints on any new venture proposals.

Although Syndeco prepared a business plan and conducted a feasibility analysis for the meter reading operation, the discussion between representatives of the parent and subsidiary organizations broke down in its early stages. These discussions had involved a number of individuals from both companies. However, most of the communication had been channeled between two individuals, representatives for Syndeco and Detroit Edison, who took responsibility for the 
collaborative effort. Both representatives attributed the breakdown to differences in determining an appropriate unit cost (cost/meter read) for the operation. This could not be resolved and, a few months later, Detroit Edison sought bids for a one-year meter reading contract from businesses outside the company. Syndeco did not bid on the contract, and portions of the contract were awarded to two other businesses.

Shortly thereafter, we were asked by Syndeco to assess the situation in preparation for other possible contract negotiations between Detroit Edison and Syndeco, including negotiation for meter reading in subsequent years. Both Syndeco and Detroit Edison supported the assessment with their time and attention during the assessment, and with remuneration to the intervener. The integrative analytical assessment led to new insights to the issues underlying the conflict and how it might be resolved. In the end, the assessment was considered by both parties to be instrumental to the consummation of a meter reading agreement between the two organizations in the subsequent year.

TABLE 1

Process Stages and Allocation of Effort

\begin{tabular}{|c|c|c|}
\hline Process Stage & Methods & Effort $(\%)$ \\
\hline 1. Initial contact and orientation & Meetings & 5 \\
\hline $\begin{array}{l}\text { 2. Qualitative assessment } \\
\text { and description }\end{array}$ & Interviews & 20 \\
\hline 3. Structuring the situation & $\begin{array}{l}\text { Structural diagrams } \\
\text { Historical diagrams }\end{array}$ & 15 \\
\hline 4. Analvtical formulation & Multi-attribute model & 15 \\
\hline $\begin{array}{l}\text { 5. Quantitative assessment of } \\
\text { interests and outcomes }\end{array}$ & $\begin{array}{l}\text { VOSDA workbook, } \\
\text { Face to-face }\end{array}$ & 10 \\
\hline $\begin{array}{l}\text { 6. Integration of quantitative } \\
\text { data for evaluation }\end{array}$ & Multi-attribute model & 5 \\
\hline 7. Analysis and interpretation & $\begin{array}{l}\text { Paretian analysis, } \\
\text { Difference analysis }\end{array}$ & 20 \\
\hline $\begin{array}{l}\text { 8. Communicating findings and } \\
\text { results }\end{array}$ & Briefing, Report & 10 \\
\hline
\end{tabular}

As applied in the meter reading case, the integrative analytical assessment was an eight-stage approach that included elements of VOSDA, Paretian analysis, and the principled negotiation process. The specific techniques and allocation of effort in each stage of the procedure are shown in Table 1, while the functions and products of the eight stages are explained and illustrated below.

\section{Initial Contact and Orientation}

The assessment can be initiated in any number of ways, if and when the conflict situation is ripe for third party intervention (Moore, 1986). However, intervention often begins with an invitation from the negotiating parties to the intervener requesting assistance. The purpose of the orientation meetings is to set an appropriate intervention agenda and to establish a climate for improved information sharing and problem solving. If conducted well, the orientation meetings should establish a constructive working relationship between the intervener and the negotiating parties, and result in an agreement on the intervention needs, a list of key questions to guide the assessment, and a workplan that has the consent of all involved. 
In the case of Detroit Edison and Syndeco, the orientation meetings followed an earlier meeting with Syndeco officials, where the intervener presented the concept and proposal for the IAA. At that meeting, the president of Syndeco agreed to submit the proposal to the top management of Syndeco and Detroit Edison for their review and possible approval.

With the approval of both parties secured, the intervener arranged an orientation meeting with the representatives of each party. This second meeting was more structured than the first and centered on the needs and objectives for the study. The intervener attempted to identify and clarify each parties questions concerning the previous failed negotiation, directing the inquiry along a path agreeable to both clients.

To begin the assessment, the intervener simply asked the representatives whether they had any questions that they would like the assessment to address. The discussions that followed uncovered a number of issues related to content of the contract, the failed negotiation process, the structure of the relationship between the parties, and the organizational climate. However, two general questions dominated the others. The most pressing question from the perspective of Detroit Edison was, "Why didn't Syndeco bid on the contract?" The representative of Syndeco was most interested in, "Why didn't Detroit Edison structure the contract to match our (Symdeco's) business plan?" Underlying these questions was the shared interpretation that the discussions broke down on the issue of the unit cost for the service.

The intervener also made a request for access to relevant documents and the cooperation of key individuals from both organizations. In this case, the most useful documents were Detroit Edison's strategic plan, Detroit Edison's specifications for the meter reading contract, Syndeco's business plan for meter reading services, a listing of meter reading performance indicators, a comprehensive study and evaluation conducted by Detroit Edison on the meter reading activities of other utilities, Detroit Edison's meter reading operations manual, and organizational charts for both parties. Assessment interviews were scheduled with eleven individuals from Detroit Edison and four individuals from Syndeco.

\section{Qualitative Assessment and Description}

'The focus shifts in this stage from identifying the parties' underlying intervention needs to describing the basic nature of the conflict situation. The intervener uses the questions identified during the orientation to guide a series of face-to-face interviews and a document review with the intent of identifying the principal factors contributing to the situation.

In this case, the intervener designed a questionnaire to identify key elements of the contract and the relationship between the parties. It addressed a broad range of general factors, including: the identity of interested parties; the unit of party identity (e.g., individual, group, organization, or some coalition); the relevant attributes of these parties (e.g., interests, aspirations, expectations, stakes, resources, reservation alternatives, routines, etc.); the negotiating positions held by these parties; any recognized options for agreement; the technological determinants of the agreement options; the attributes of the relationship between the parties (e.g., power and interdependencies, communication structure, normative structure, institutional environment, etc.); and possible interpersonal factors that influenced previous encounters. The intervener was specifically 
requested by the top management of both parties to delve into the question of personalities and their influence on the negotiation.

The intervener interviewed eleven individuals from Detroit Edison who had either been involved with formulating the contract specifications or involved in the actual negotiations with Syndeco. These individuals spanned several levels of the organizational hierarchy, from the supervisor of meter reading services to the Vice President of Division Operations. They also represented a variety of backgrounds and interests in the organization, including operations, marketing, financial, regulatory, and legal perspectives.

Syndeco, being a smaller organization, had fewer people involved in the meter reading negotiation. The intervener interviewed the president and three vice presidents of the subsidiary, representing operations, marketing, and the financial perspectives on the situation.

In addition to the interviews, the intervener reviewed the documents provided by Detroit Edison and Syndeco, becoming familiar with the written plans and specifications related to the case. These documents were helpful in deciphering the details of the positions of each party. They also explained the technical aspects of operating a meter reading business. The information gleaned from these documents was used to suggest leads and to support and confirm the statements made in the interviews.

The interview and document data yielded findings for each of the study questions and suggested an initial structure for the formal analytical assessment model. The interviews uncovered useful qualitative information regarding the organizational climate and incentive structure. For example, the interviews revealed that the employees at the operational level of Detroit Edison were ambivalent about providing support for their subsidiary Syndeco. This ambivalence was tied to top management's uncertainty regarding Syndeco's strategic role in the corporation, and was perpetuated by an impending reevaluation of Detroit Edison's overall strategic plan. This type of finding was useful in developing recommendations aimed at improving the climate for future negotiations between Detroit Edison and its subsidiary.

\section{Structuring the Situation}

The third stage of the assessment bridges the qualitative description and the analytical formulation of the conflict. Starting with the unstructured qualitative information from the previous stage, the intervener assists the representatives in constructing an abstract but explicit conceptual diagram of the negotiation. It involves synthesizing the information from the interview and document findings and making explicit assumptions about the relationships between different elements of the situation and the final outcome of the negotiation. The process supports systematic and intuitive assessment while building a structure on which to base an analytical formulation of the situation in successive stages.

The intervener initiated the structuring process by reviewing the qualitative assessment data and building two "straw man" diagrams of the negotiations for each party. ${ }^{2}$ These diagrams were designed to be flexible, with moveable boxes and arrows, for easy modification by the representatives. The first diagram was a static representation of the key variables and relationships synthesized from the qualitative assessment in the previous stages (Diffenbach, 1982). It emphasized decision variables (e.g., actions, contract terms, etc.), measures of each party's 
objectives, and variables that intervened between the decisions and measures. This diagram would be used later to initiate the formulation of the analytical problem. The second diagram depicted the history of the earlier negotiation, identifying events, meetings, and decisions that affected the negotiation process. The historical diagram was useful in diagnosing obstacles in the negotiation process and in identifying bargaining strategies that were employed in the failed negotiations.

When completed, the intervener presented the diagrams to the representatives for their review and modification. With the assistance of the intervener, each party assessed and modified this framework, identifying factors that contributed to the outcome of the failed negotiation. The diagrams addressed the parties' interests, agreement variables, related outcomes, and criteria for evaluating the outcomes. When the diagrams took on a form that was agreeable to the representatives, they were then presented to a wider audience for further comments and modifications. The audience included the interview participants, the representatives of the other party, and the division vice-presidents.

As a final step, the intervener asked the representatives to bound the assessment by marking directly on the structural diagram those elements that the intervener should address. In both instances, the representatives wanted all of the variables and their relationships to be addressed.

\section{Analytical Formulation}

The evaluation of the agreement alternatives is formulated as a multi-attribute utility problem (Keeney and Raiffa, 1976). To initiate the formulation process, the intervener uses the structure from the previous phase to construct a requisite quantitative model of the negotiation (Phillips, 1984). This model is designed to clarify influential agreement variables, to guide the intervener's collection and use of the quantitative data, and to provide a rational basis for prescribing possible agreement options. The multi-attribute formulation involves identification and selection of appropriate attributes, and development of attribute anchor points and metrics. It also involves accurate definition of agreement scenarios.

The intervener for the meter reading assessment used the situation diagrams to identify an initial set of attributes for developing and evaluating alternative contract scenarios. As in the other stages, the initial formulation was presented to the representatives of the two parties for their review, modification, and elaboration. A complete set of attributes emerged as the intervener led the representatives through several passes of the attribute definition process. Throughout this activity, the intervener took care to assure that the attributes reflected specific scenario outcomes, and that additive independence assumptions applied. Additive independence between the attributes is important because it permits relatively simple mathematical integration of the quantitative assessment data. The total value of each agreement scenario is simply the weighted sum of the values of the attributes.

Detroit Edison's objectives, from the meter reading operations perspective, included low unit cost for the contract, a competitive service plan, profitability for Syndeco, operational flexibility, and high service quality. Syndeco's objectives included flexibility in operating the meter reading business, freedom to employ new technology, high business growth potential, a positive relationship with Detroit Edison, contract continuity, and a small cash flow burden. Both the 
attributes and outcomes were designed to reflect these objectives. The formal translation of these objectives is presented in Table 2 .

TABLE 2

Attributes and Their Weights

\begin{tabular}{lclc}
\hline \multicolumn{1}{c}{ Detroit Edison } & & & \multicolumn{2}{c}{ Syadeco } \\
\multicolumn{1}{c}{ Attribute } & Wt. & \multicolumn{1}{c}{ Attribute } & Wt. \\
\hline 1. Cost/read & 40 & 1. Route assignment & 17 \\
2. Route assignment & 15 & 2. Technology & 17 \\
3. Number of contractors & 15 & 3. Projected growth & 14 \\
4. Syndeco's profits & 15 & 4. Relations with DECo. & 13 \\
5. Skipped meters & 5 & 5. Contract duration & 12 \\
6. Misteads & 5 & 6. Cost/read & 2 \\
7. Customer service & 3 & 7. Labor relations & 9 \\
8. Labor relations & 2 & 8. MPSC difficulties & 6 \\
\hline
\end{tabular}

"MPSC is the Michigan Public Service Commission which might object to Syndeco's

To complete the formulation, each representative described two scenarios in terms of the defined attributes, their latest offer and the best alternative use of their resources if not used in this meter reading agreement. There were three scenarios in all, each party's position and the no-agreement alternative. The attributes provided a consistent outline for the representatives' scenario descriptions. The parties position scenarios are summarized in Table 3 which highlights the parties' differences. The parties thought that several of these differences were relatively insignificant (for example, benefit requirements, control measures, etc.) which explains why they are not reflected in the parties' attributes (Table 2).

\section{Quantitative Assessment of Interests and Outcomes}

Once the attributes and scenarios are identified, the intervener assesses the negotiator's interests and expectations regarding the contract outcomes. The quantitative assessment not only provides data for the analysis, but also assists the representatives of each party in clarifying their expectations and priorities regarding the alternative contract options.

To operationalize the quantitative assessment for Detroit Edison and Syndeco, the intervener followed the workbook approach developed for a VOSDA (valueoriented social decision analysis) that had been used to evaluate alternative energy futures for the State of Michigan (Chen and Mathes, 1986). The intervener assembled an assessment workbook for the representatives to complete that consisted of descriptions of the agreement scenarios, a worksheet for selecting and weighting attributes, and worksheets for assigning probabilities and utilities to the defined range of outcomes. The workbooks were then distributed to the representatives of each organization and other selected individuals whose perspectives were considered important. The representatives completed the workbooks, assigning values and probabilities to the range of outcomes on each attribute, assigning relative weights to each attribute, and then returned the workbook to the intervener.

Following completion and collection of the workbooks, the intervener repeated the assessment in face-to-face interviews with the participants. Both 
TABLE 3

Summary of Positions Described in Scenarios

\begin{tabular}{|c|c|c|}
\hline $\begin{array}{l}\text { Contract } \\
\text { Characteristics }\end{array}$ & $\begin{array}{l}\text { Detroit Edison (DECo.) } \\
\text { Position }\end{array}$ & $\begin{array}{l}\text { Syndeco } \\
\text { Position }\end{array}$ \\
\hline \multicolumn{3}{|l|}{ Contract Duration: } \\
\hline 1st period & 1 year & 2 years \\
\hline 2nd period & 3 years & 5 years \\
\hline Number of Contractors & 2 & 1 \\
\hline \multicolumn{3}{|l|}{ Cost of Service: } \\
\hline 1st year & $\$ 0.28 / \mathrm{read}$ & $\$ 0.495 / \mathrm{read}$ \\
\hline by 5 th year & $\$ 0.28 / \mathrm{read}$ & $\$ 0.30 / \mathrm{read}$ \\
\hline Benefit Requirement & $7.5 \%$ immediate & $5 \%$ delayed vesting \\
\hline Route Assignment & daily by DECo. & permanent \\
\hline Route Configuration & variable & contiguous \\
\hline Technology & manual only & $\begin{array}{l}\text { manual (yrs. } 1 \& 2 \text { ), } \\
\text { electronic (yrs. 3+) }\end{array}$ \\
\hline Control & $\begin{array}{l}\text { penalty specification, DECo. } \\
\text { verification, field checks }\end{array}$ & $\begin{array}{l}\text { hand-held devices, DECo. } \\
\text { verification }\end{array}$ \\
\hline
\end{tabular}

the workbook and interview assessments were then compared for consistency and modifications were made where necessary. The final sets of attributes and their weights are presented in Table 2 . The ordinal rankings are given on the left and the cardinal weights (100 point scale) are given on the right for each set of attributes.

The intervener may employ one of a number of alternative techniques for assessing probabilities, utilities, and the attribute weights (von Winterfeldt and Edwards, 1986). Although there is a tradeoff between the complexity and precision of these techniques, several factors led the intervener to select the simple workbook approach in this case. First, the intervener believed that the workbook approach would be easy for the study audience to understand. Second, it required less time from the representatives and allowed more time for checking the data through repeated assessment. Finally, the multi-attribute value model was used primarily for pinpointing differences and sensitivities in values and expectations, which form the basis for joint gains. This type of sensitivity analysis can be accomplished with a relatively low level of precision (Phillips, 1984).

\section{Integration of Quantitative Data for Evaluation}

In this stage, the intervener performs the mathematical integration of the quantitative assessment data to generate joint evaluations of the agreement scenarios for each party. This can be performed as a series of hand calculations or by designing an appropriate computer model for calculation of the multi-attribute values. Once generated, these values are then plotted and compared on a joint evaluation graph.

The selection of an appropriate model for integrating the data depends on the attribute independence assumptions that hold. Although the intervener may take measures in earlier stages to help assure that the additive independence assumption applies, this is not known for certain until all the data has been collected and the assumptions are tested. If the attributes are not found to be additively independent, then other less restrictive assumptions may be tested or 
the attributes can be revised and the values reassessed (von Winterfeldt and Edwards, 1986).

\section{FIGURE 2}

Joint Evaluations and Efficient Frontier

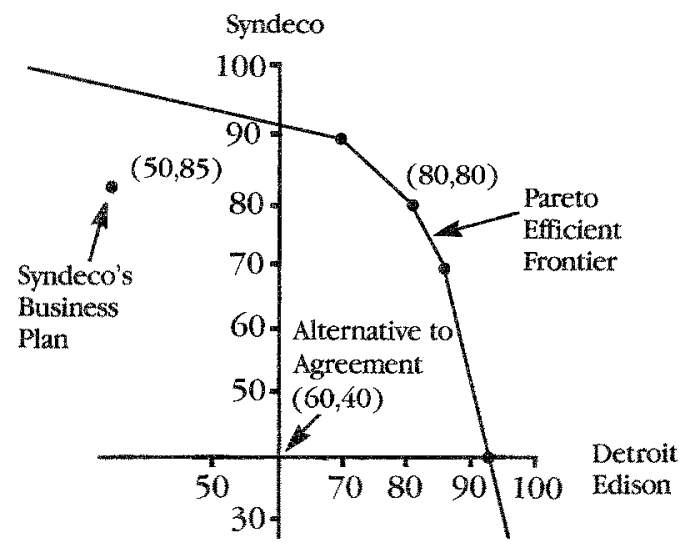

For the meter reading problem, the intervener assumed additive independence. Generation of the multi-attribute values for the agreement scenarios required translation of the additive multi-attribute formulation into a computer model, input of the assessment data, and computation of the results. The quantitative joint evaluations for each agreement scenario are illustrated in Figure 2 . The values have been rounded for clarity of presentation.

\section{Analysis and Interpretation}

This stage of the assessment uses the initial qualitative and quantitative findings to suggest opportunities and means for improving integrative bargaining. The process involves determining the range of efficient contracts, exploring the sensitivity of outcomes to changes in the data and the model parameters, identifying possible modifications in the contract that could lead to joint improvements, and incorporating the qualitative findings in support of the quantitative findings.

The relative quantitative rankings of the meter reading contract scenarios were consistent with the parties intuitive rankings. However, the rankings themselves provided little additional insight into the situation. The real benefit of the quantitative assessment data was derived from their use in the analysis. The intervener used the multi-attribute utility functions of the parties to determine a set of efficient contracts that exploited the full potential for joint gains as defined by the functions (Raiffa, 1982; Barclay and Peterson, 1976). These contracts constitute an efficient Pareto frontier that bounds the set of all feasible contracts (see Figure 2). By generating efficient contracts that were superior to the no-contract alternative for both parties, the intervener had a potent tool for convincing both parties of the value in continuing their negotiation. Although the representatives voiced skepticism in the political feasibility of the efficient contracts, the possibility of joint gains served as a strong incentive to resume negotiation and as a point of departure for further discussions on the meter reading contract. 
Perhaps of more direct influence in the negotiation was the demonstration of potential arrangements that could lead to superior agreements. The intervener performed a sensitivity analysis on key variables and found opportunities to create value through common interests, synergy, and tradeoffs on differences (Sebenius, 1984). For example, the intervener identified two attributes that were in direct conflict but valued differently by the parties. These were cost of the meter reading operations, which was valued more by Detroit Edison, and management flexibility, which was valued more by Syndeco. The analysis showed that both parties could gain if Syndeco would reduce its charge in return for greater flexibility in managing the operation.

Following the formal analysis of the situation, the findings and insights from the quantitative analysis were synthesized with the findings from the earlier qualitative assessment. The findings from each were compatible and provided a means of triangulation on the situation. The qualitative data provided a rich description of the negotiation while the formal models provided objective data and rational analysis which improved communication on the relationship between agreement options and the parties' interests.

\section{Communicating Findings and Results}

Use of the findings and recommendations depends on the original purpose of the assessment and form of intervention it supports. The IAA approach can be used as a stand-alone method or as a means of support for other forms of intervention including mediation, arbitration, and fact-finding efforts. Each of these contexts may require a different approach and strategy for reporting the results of the assessment.

In this case, the intervener applied IAA as a means of exploring the value of resuming negotiation in this particular case and other cases like it. If the parties decided to resume their negotiation, they would continue without the assistance of the intervener. Other than in the final presentation, the intervener did not get actively involved in assisting the face-to-face communication between the parties. In fact, by conducting separate assessment interviews with the representatives of the organizations, the process supports the behavioral prescription of separating the people from the problem (Fisher and Ury, 1981). Once the analysis and interpretation were completed, communication of the findings and results was more a matter of presentation than strategic application.

The presentation involved the production of a summary report and a joint briefing session involving several members from each of the organizations. Many of the findings have already been described. The recommendations included substantive and procedural prescriptions. In addressing the social and organizational factors, the report recommended (1) defining Syndeco's role with respect to the parent organization, (2) educating operational level managers about Syndeco's role and its importance to Detroit Edison, (3) providing top-down incentives for cooperation to modify the payoff structure, and (4) working together to develop a single business plan instead of devising separate plans as in the previous negotiations. The principled negotiation process (Fisher and Ury, 1981) was also described and recommended as an approach for future negotiations.

The intervener also presented one option for generating a win-win outcome as an example of how joint gains could be created through tradeoffs on conflicting 
attributes. The example was presented for pedagogical purposes and the negotiators were encouraged to use a similar calculus, based on the assessment, to devise their own win-win agreements. The actual application of the results was left to the representatives of Syndeco and Detroit Edison. As indicated previously, the two parties reached an agreement in the negotiation of a contract for meter reading services in the subsequent year.

\section{Conclusion}

What was developed and demonstrated in the Detroit Edison-Syndeco case is an integrative analytical assessment of a negotiation that had already taken place. In this sense, the analysis and assessment were mainly retrospective. There was a clear history of negotiation between the two parties and the intervener used problems from past negotiations to develop prescriptions for the future. On the other hand, the two parties expected to enter into other similar negotiations and were motivated by the need and hope for better cooperation in the future. Furthermore, the quantitative assessment was based on the current values and beliefs of the parties, not on recollections of the past. The end result was a mutually satisfactory agreement through the subsequent negotiation. In this sense, the integrative analytical assessment procedure was applied as if it was during an ongoing negotiation. Our experience with the procedure, therefore, led us to believe that it would be equally helpful to retrospective and ongoing negotiation assessments.

The authors believe the assessment was instrumental in promoting agreement because it facilitated ongoing and future negotiations in several respects. First, it provided an opportunity for the parties to reopen discussions on the contract in a more cooperative and less threatening context. The assessment was nonbinding, and interpersonal factors were dissipated in the absence of direct ongoing contact negotiations between the representatives. Second, the process and the context encouraged the representatives to set aside their current positions and to reconstruct their assessment of the situation from scratch. The reconstruction focused more on the underlying interests and means of reaching mutually satisfactory agreements than on the positions and strategic activities of the other party's representatives. Moreover, it gave the members of both parties a glimpse at the interests and constraints that motivated the other party's behavior in past and future negotiations. This helped in explaining the difficulties encountered in the previous round of discussions and it suggested means for avoiding those difficulties in the future.

Third, the systematic and consistent assessment procedures improved communication between the parties. The assessment was symmetrical with respect to the involvement of the parties, with the representatives participating in identical and straightforward assessment procedures. As a consequence of their active involvement, the participants developed an intuitive feel for the strengths and limitations of the procedure and the corresponding validity of the information the procedure generated. The extensive dissemination and use of the assessment results by both parties is evidence of the face validity attributed to the procedure. Fourth, although an "efficient solution" was not immediately embraced by both parties, the quantitative analysis and joint optimization of the parties' value functions demonstrated convincingly that joint gains could be had through cooperation. The analysis not only suggested an array of possible options 
for joint improvements, but more importantly, it also provided a renewed incentive for both sides to reap the potential, and until that time ambiguous, benefits from a cooperative business arrangement.

In sum, the integrative analytic assessment is an operational procedure for facilitating conflict resolution that integrates the process and the analytical perspectives. Admittedly, the demonstration of its practical application to a case of parent-subsidiary negotiation is only a modest success in the wide spectrum of business negotiations, let alone many other types of negotiations in the real world. However, the authors feel that the potential for expanding the range of IAA applications is great. As Howard Raiffa (1985) put it, "What is desperately needed are a few success stories of analytical interventions in some not-too-horrendous conflicts." We hope the Detroit Edison-Syndeco case in this article is one of these needed stories.

\section{NOTES}

The authors wish to thank the Detroit Edison Company and Syndeco, Inc. for their sponsorship of, and participation in, the negotiation project, and for their permission to use the general data from the project in the preparation of this article. Kan Chen was responsible for the general concept of the IAA approach, and Steven Underwood directed the Detroit Edison-Syndeco project where he developed and tested the specific IAA procedures described here. Preparation of this article was supported, in part, by a grant from the Program on Conflict Management Alternatives at the University of Michigan.

1. Paretian analysis-named after the Italian economist, Vilfredo Pareto-is a term used in economics. A settlement is called "pareto optimal" if there is no other agreement that all of the disputants prefer; it is "pareto superior" to another settlement if all of the disputants prefer the first to the second settlement.

2. Readers interested in copies of these detailed diagrams may obtain them by writing to the programs on Conflict Management Alternatives, Center for Research on Social Organizations, The University of Michigan, 4501 LSA, Ann Arbor, Mich. 48109-1382.

\section{REFERENCES}

Barclay, S. and Peterson, C. (1976). "Multiattribute models for negotiations." Technical Report 76-1. McLean, VA.: Decisions and Designs, Inc.

Brams, SJ. (1975). Game theory and politics. New York: Free Press.

- (1985). Superpower games: Applying game theory to superpower conflict. New Haven, Conn.: Yale University Press.

Chen, K. and Mathes, J.C. (1986). "Clatifying complex public policy issues: A social decision analysis contribution." In Interdisciplinary planning: A perspective for the future, ed. M.J. Dluhy and K. Chen. New Brunswick, N.J.: Rutgers University.

Chen, K., Mathes, J.C.,Jarboe, K.P., and Wolfe,J. (1979). "Value-oriented social decision analysis: Enhancing mutual understanding to resolve public policy issues." IEEE Transactions on Systems, Man, and Cybernetics SMC-9:567-580.

Diffenbach, J. (1982). "Influence diagrams for complex strategic issues." Strategic Management Joumal 3:133-146.

Dutton, W.H. and Kraemer, K.L. (1985). Modeling as negotiating, Norwood, N.J.: Ablex Publishing.

Fisher, R. and Ury, W.L. (1981), Getting to YES: Negotiating agreement without giving in. Boston: Houghton Mifflin.

Fraser, N.M. and Hipel, K.W. (1984). Conflict analysis: Models and resolutions. New York: NorthHolland.

Greenbaum, M.L. (1986). "Process and the professional practitioner" Negotiation Journal 2:225-231.

Holling, C.S., ed. (1978). Adaptive environmental assessment and management. Chichester: John Wiley and Sons. 
Isard, W. and Smith, $C_{.}$(1982). Conflict analysis and practical conflict managernent procedures: An introduction to peace science. Cambridge, Mass: Ballinger Pub.

Keeney, R.L. and Raiffa, H. (1976). Decision with multiple objectives: Preferences and value tradeoffs. New York: Wiley.

Lax, D.A. and Sebenius, J.K. (1986). The manager as negotiator. New York: Free Press.

McDonald, J. (1975). The game of business. Garden City, N.Y.: Doubleday.

Moore, C.W. (1986). The mediation process: Practical strategies for resolving conflict. San Francisco: Jossey-Bass.

Phillips, L.D. (1984). "A theory of requisite decision models." Acta Psycbologica 56:29-48.

Quinn, R.E., Rohrbough,J., and McGrath, M. (1985). "Automated decision conferencing: How it works." Personnel 49-55.

Raiffa, H. (1985). "Mock pseudo-negotiations with surrogate disputants." Negotiation Journal 1:111-115.

(1982). The art and science of negotiation. Cambridge, Mass.: Harvard University Press.

Sebenius, J.K. (1984). Negotiating the law of the sea. Cambridge, Mass.: Harvard University Press.

von Winterfeldt, D. and Edwards, W. (1986). Decision analysis and behavional research. Cambridge: Cambridge University Press.

von Winterfeldt, D. and Keeney, R.L. (1983). "Value tree analysis as a tool for analyzing conflicting objectives." Paper presented at the Ninth Research Conference on Subjective Probability, Utility and Decision Making, Groningen, Sweden. 